\title{
The Design Representation of Image Modeling Illustrations of the legend of Xibe Nationality
}

\author{
Dong Yan ${ }^{1, a}$ \\ ${ }^{1}$ Dalian University Of Science And Technology, Dalian, Liaoning, China \\ a274261074@qq.com
}

\begin{abstract}
Keywords: Common Elements, Multidimensional Integration, Exaggerated Deformation, Symbolic Meaning, System Integration

Abstract. Relying on image design, illustration, modeling, symbiosis, space and time, system integration, as well as sone other design concepts, the image of the Xibe Nationality legends has been shaped to improve the promotion and dissemination of Xibe's regional visual symbols. Through the analysis of heroic deeds from narrative Xibe Legends, the character of these legends has been generalized and summarized. Indeed, the thinking method of image modeling provides a new way of consideration for the remoulding of legendary illustrations. Through the use of common elements, multidimensional integration, exaggerated deformation, symbolic meaning, system integration, together with creative methods of image creation, the issues such as design representation of illustrator characters can be solved.
\end{abstract}

\section{Introduction}

A The Xibe nationality is mainly distributed in the northeast and Xinjiang area. Today, a series of traditional activities such as archery, horse riding, wrestling and fighting for sheep are still preserved by this nation. Because of the popularity of Tibetan Buddhism and Shamanism, the Xibe people hold their traditional festivals such as Westward Migration Festival and Discredit Festival every year. All these reflect the situation of fishing, hunting, nomadic existence, living environment, spiritual belief, daily production and living customs in the Xibe tribe era. Here, mainly through the analysis of the historical deeds of the legend from the Xibe Nationality, the illustrations of the images about the legendary figures can be molded, so as to better spread and promote the culture of the Xibe Nationality. There are many editions of the legends from the Xibe Nationality, among which "The Xibe nationality's novel of Hejunyou" is relatively complete and highly circulated. It systematically traces the history of the origin and development of the Xibe people, as well as the process of its formation and evolution, which is regarded as "the living epic of the Xibe Nationality"[1]. And also, the author once lived in Liaoning Province, the native place of Junyou He, which is quite convenient for on-the-spot investigation.Here,it mainly creates illustrations based on legend and group illustration from "The Xibe nationality's novel of Junyou He".

\section{Analysis of Legendary Deeds of Xibe's Novel form Junyou He}

\section{The analysis of the Legendary Figures of the Xibe Nationality}

Through the narrative description of legendary deeds, many great characters with different personalities and personalities have been molded in the Legendary Deeds of Xibe's Novel form Junyou He, such as Xili the mother, the Western expedition general, Furonge, the filial girl who saved her father, and Tuoba Huai, the man who unified the Xianbei. And the following list is a detailed analysis of it. The heroic characters depicted here are heroic, intelligent, kind and filial. These stories are relished for the thousand years by Xibe people.

The Analysis about the Plot Elements within the Novel of the Xibe Nationality

There are two standards for the plot of storyline: the one is a specific event or case, and the other is a specific occasion, background, or spatial layout[2].And the following list makes a detailed analysis of it. (Table 1) 
Table 1 An analysis of the story about male Legends

\begin{tabular}{|c|c|c|}
\hline $\begin{array}{l}\text { Story } \\
\text { theme }\end{array}$ & The type of story plots & $\begin{array}{l}\text { The novel plots of the Xibe } \\
\text { Nationality }\end{array}$ \\
\hline Battle & $\begin{array}{c}\text { Fighting, siege warfare, } \\
\text { comprehensive war, military } \\
\text { screen, military movement, } \\
\text { ambush, and talks }\end{array}$ & $\begin{array}{l}\text { westward march of Xili the mother, } \\
\text { Tanshihuai unified the Xianbei }\end{array}$ \\
\hline $\begin{array}{l}\text { Send off } \\
\text { and } \\
\text { movement }\end{array}$ & Sergeant, businessman, traveller & Wuchulexi’s Roaming Mind \\
\hline $\begin{array}{l}\text { Eavesdrop } \\
\text { ping and } \\
\text { peeking }\end{array}$ & Eavesdropping, curiosity & $\begin{array}{l}\text { The god Bohe eavesdropping on the } \\
\text { Golden State }\end{array}$ \\
\hline $\begin{array}{l}\text { Finding an } \\
\text { Inn on } \\
\text { street }\end{array}$ & Customs & $\begin{array}{l}\text { Miracle-working doctor huangke } \\
\text { living in the inn on the way }\end{array}$ \\
\hline $\begin{array}{c}\text { Wall } \\
\text { building }\end{array}$ & Architecture, Landscape & Xili back to Tribes \\
\hline $\begin{array}{l}\text { Shooting } \\
\text { and } \\
\text { Hunting }\end{array}$ & Life & $\begin{array}{l}\text { The god Haierzhan teaching the } \\
\text { hourse riding }\end{array}$ \\
\hline Dream & Fantasy & Strange dreams, etc. \\
\hline
\end{tabular}

Through the analysis of the the story theme, some plot in the story can be used to create others.

\section{The analysis of the Scene Elements within the Novel of the Xibe Nationality}

Rich resources, such as Large tracts of mountains, forests, grasslands, wild horses, tigers, wolves, black bears, roe deer and deer are all described in the novel. An inhabited tribal life is the native cultural environment here. Xibe's ancestors were mainly composed of tribes of the same family name. However, several of them were living together, with fishing, hunting and nomadic as their daily events. And the following table makes a detailed analysis of it. (Table 2)

Table 2 Analysis of the Characteristic Scene Elements of the Xibe Nationality

\begin{tabular}{|c|c|c|c|}
\hline $\begin{array}{c}\text { Clothes \& } \\
\text { Accessories }\end{array}$ & Architecture & Utensils & Written words \\
\hline $\begin{array}{l}\text { Animal skin } \\
\text { embroidery, fish skin } \\
\text { or cortex armour. } \\
\text { The tribute silk from } \\
\text { some South } \\
\text { countries, commonly } \\
\text { used clothing such as } \\
\text { bear skin, horsing } \\
\text { boots, sheepskin, } \\
\text { etc. }\end{array}$ & $\begin{array}{c}\text { Tents, cellar, } \\
\text { cave, a wall that is } \\
\text { simply } \\
\text { surrounded by } \\
\text { branches and } \\
\text { stones }\end{array}$ & $\begin{array}{l}\text { Harness, birch } \\
\text { products, kumiss, } \\
\text { milk wine, colorful } \\
\text { boots, felt bridal } \\
\text { chamber, trigger } \\
\text { that can order the } \\
\text { army, rewarded } \\
\text { sword, jewel, etc }\end{array}$ & $\begin{array}{l}\text { Deformed on the } \\
\text { basis of } \\
\text { Manchu,(word) } \\
\text { head, (word) } \\
\text { tooth,(word) circle, } \\
\text { (word) point, } \\
\text { (word) tail. } \\
\text { Different kinds of } \\
\text { leftfalling stroke } \\
\text { and vertical line } \\
\text { connecting letters }\end{array}$ \\
\hline
\end{tabular}


These characteristic scene elements reveal national characteristics in clothing, architecture and utensils. After converting words into graphics, the important role of Xibe's characteristics has been highlighted.

\section{Illustration Design Conception of Xibe Legends under the Idea of Image Modeling Thinking}

\section{The Idea Construction of Image Modeling Design}

The word "image" first appeared in the The Book of Changes, "Hsi Tzu". The sage set up an image to express his meaning as much as possible, who advocated the combination of subjective and objective. Image is set up to express the meaning as much as possible. If the meaning has been obtained, the appearance is indifference[3]. Xibe's legendary characters are all have distinct characters with outstanding deeds. By studying the character, behavior characteristics, heroic achievement and background of the characters depicted in the Legendary Deeds of Xibe's Novel form Junyou He, character modeling, image plot combination, and image scene are designed and conceived under the idea of image modeling thinking, which originated from the principle of image modeling based on symbiotic combination, compound space-time and system integration.

\section{The Design Conception of Image Figure Modeling}

Symbiotic isomorphic modeling refers to two or more image elements sharing a space. Therefore, a part of the same contour line or figure can form a completely new and refreshing figure. With the idea of image modeling, collage isomorphic figure can highlight the best image of the illustrator, according to the layout of the theme, which grasps rhythmic rhythm, multi dimensional emphasis with modeling actively screens vivid and meaningful plots exaggerated. ${ }^{\text {(Fig. 1,Fig. 2) }}$

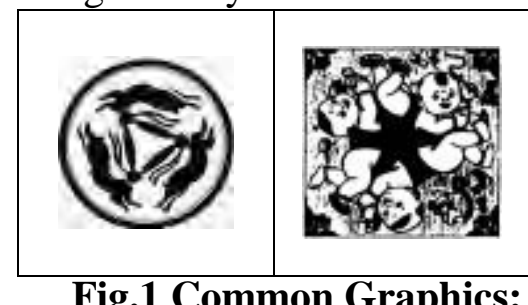

Fig.1 Common Graphics: Three rabbit flying alga, Six head chasing on the well, Horses eat grass
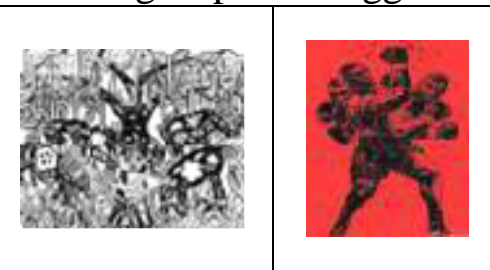

Fig.2 Multidimensional Collage

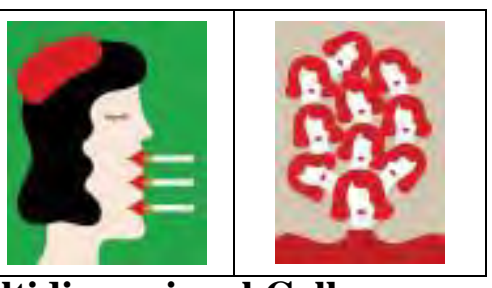

Collage

\section{Facial Modeling Design to Embody the Wisdom of the Xibe People}

Since ancient times, the physiognomy has existed in China. Through the study of the face appearance, the Chinese people can tell a person's character and conduct. From the characteristics of human appearance, we can roughly deduce a person's economic conditions, personality and so on. The folklore has a view of "person's face is shaped by their heart". Most of the people with warmly heart are close to each other, while the ones with negative emotions are not easy to get along with[4]. "Observant and alert", a sign of a clever man, is the essence that folk people consider as capable talent. The Guanyin Buddha has thousands of eyes, thousands of hands and four faces. This form is the reflection of such thought.

\section{Multidimensional Limb Modeling Design to Embody High-frequency Movement of Characters}

The application of the trajectory, for example, the swing process of the hand appears as multiple hand images on the track, is just like the continuous exposure of photography. This form is used in many modern illustrations.

\section{Hyperbole Shape Design to Embody Character and Nature of a Person}

The modular method of body modeling can be used for the proportionate exaggeration of the body. Part of the hyperbole is created under the reorganization of symbiotic and creative graphics, so as to coordinate the whole. Graphic symbols methods have been borrowed to highlight the character disposition of the characters to achieve the purpose of illustration creation. ${ }^{\text {(Fig. 3) }}$ 


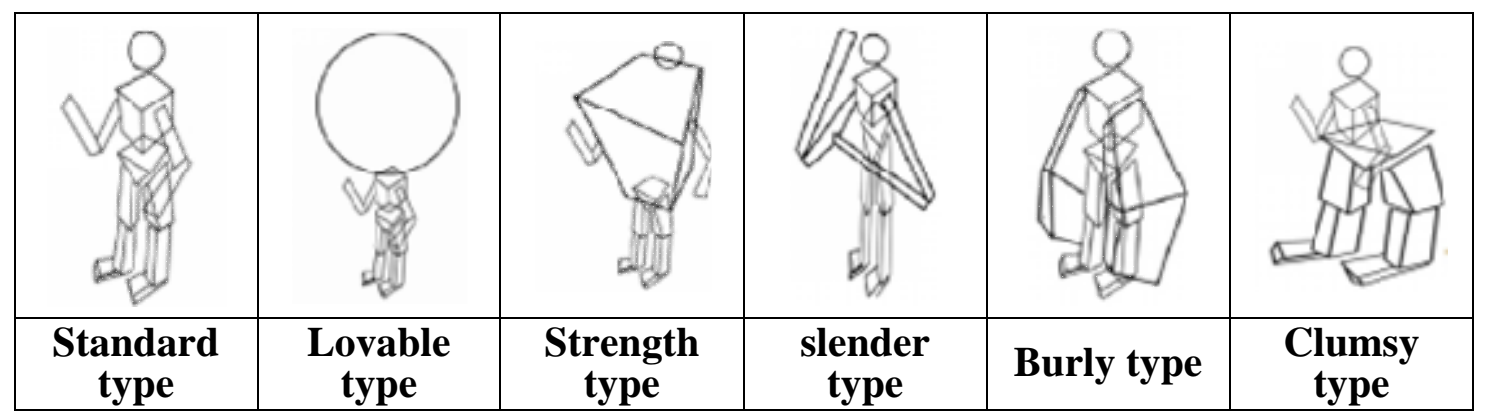

Fig. 3 The proportionate hyperbole of the human body

\section{The Plot of the Xibe Nationality Novel in Combination with Time and Space}

\section{A Combination of Plot Elements that Highlight the Symbolic Implication}

The illustrations depicted in costumes, landscapes, buildings and utensils are not only the background of stories, but also play a role in describing the story space[5]. Because of the artistry of the story, the integration of objects in different periods of time has also made the illustrations work with the characteristics of the times. Here are some of the elements of the Xibe ethnic group that I have searched for long time. ${ }^{\text {(Fig. 4) }}$
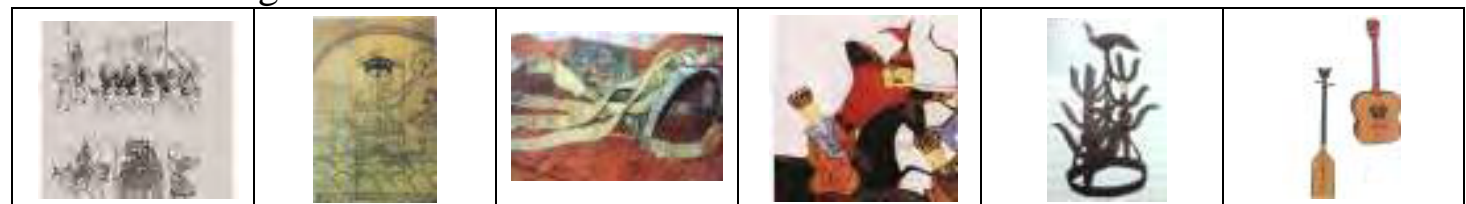

Fig. 4 Allegorical symbol with characteristic elements of the Xibe Nationality

\section{A Complex Representation Reflected Time and Space}

The plot arrangement is very important for narrative illustration. An excellent illustration can explain the plot of a story through a simple picture and make people guess the author's potential intention. Narrative illustrations, like narrative literature, make people feel lingering charm and well-timed. (Fig. 5)

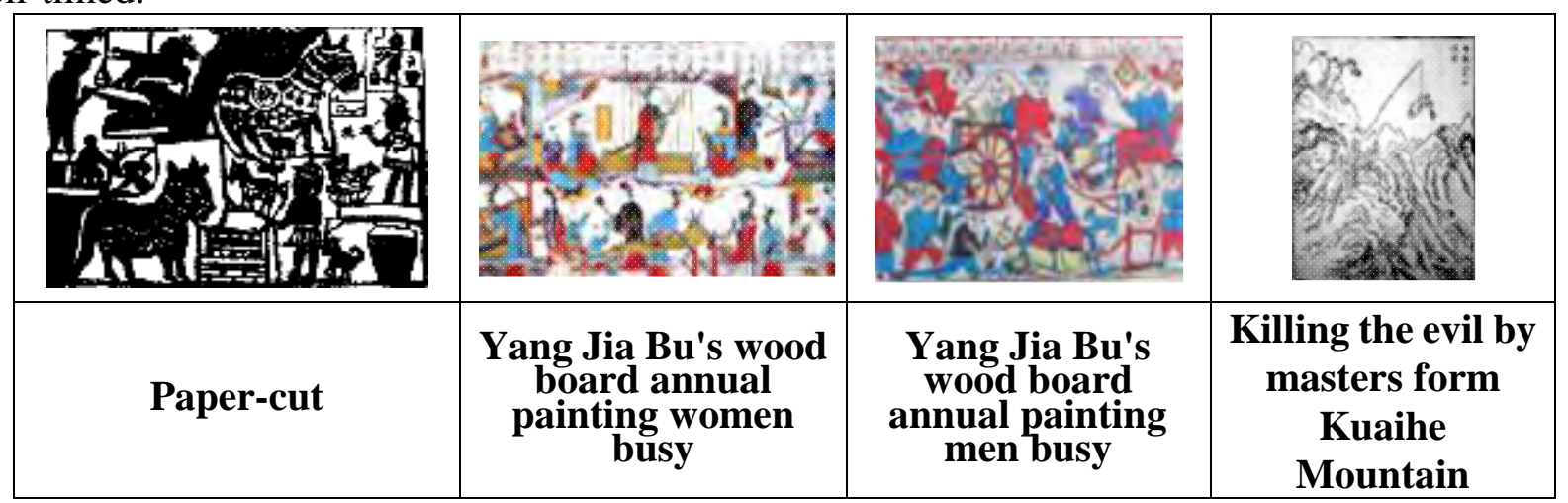

Fig. 5 Image plot combination of space and time

These narrative illustrations are the integration of sentimental festivals and symbolic elements. The theme of the legendary deeds of Xibe's novel form Junyou He does not use the usual schema of the past literary illustration, but is based on the understanding of the text for illustration creation. And there are several plot patterns in the content of one illustration, which requires the layout of composite space-time.

\section{Scene Representation of Systematic Integration within Xibe's Novel}

For a similar story or plot mode, the theme, character and style of the work determine the composition of the scene. The illustration composition is all about how to arrange the three elements of the characters, the plot and the scene. By arranging the narrative time and space, the story is carried out and the scene is patterned. 


\section{Analysis of the Creation Process of Image Modeling Legend Illustration}

\section{Multifaceted Modeling of Common Elements for Legends}

In the legendary deeds of Xibe's novel, the head shape of heroine comes from the ancestor god, Xi the mother. Common elements, with three eyes and two ears, have been used to achieve multifaceted effect. This kind of diachronic visual language, turning from the right to left movements of the face, is the process of deducing the role movement in time. By handling rhythm, exaggeration and distortion, the psychological characteristics of Xili the mother can be shown[6]. ${ }^{\text {(Fig. 6) }}$

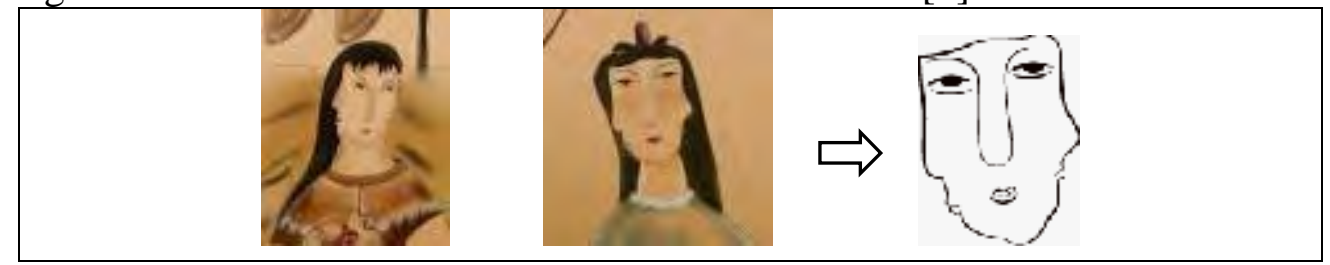

Fig. 6 Multifaceted Modeling

Multidimensional Body Modeling Reflecting Rhythm of Motion

The multi dimensional modeling of legends is often accompanied by the exaggeration of multiple positions. It can also exaggerate any part of the body as needed. In the animal role multi dimensional limb assembly modeling, such as Da Lu Hong's horse (or beast) for riding, double head or multi-head might been seen by us. By describing the rhythm of action, on the one hand, the symbolism of character can be explained by shaping the character through movement time, which made it easy to be identified. On the other hand, the vitality of the role can be strengthened by the changing time combination of the following and overlapping principles in photography, which made the role more lively and vivid. (Fig. 7)
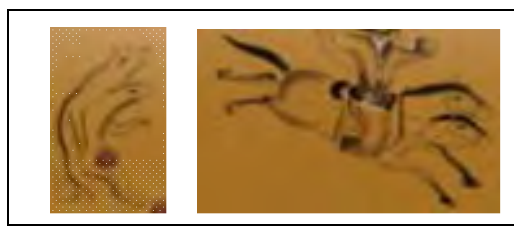
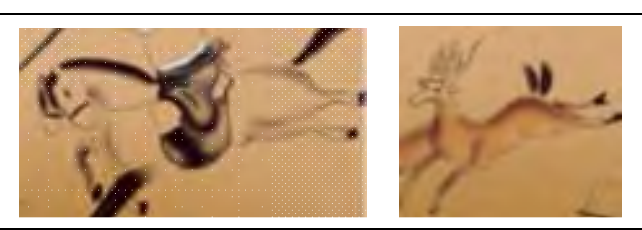

Fig. 7 Multidimensional modeling of animals

\section{Image Modeling Generalized a Highly Exaggerated Body Shape}

When designing a body type for a legendary figure, the advantage of human modeling is that it has great freedom in space. However, the female legend embodies the body image modeling of rigidity and flexibility, while the male legend is the coexistence of power and wisdom. They are interesting and unforgettable for us. (Fig. 8)

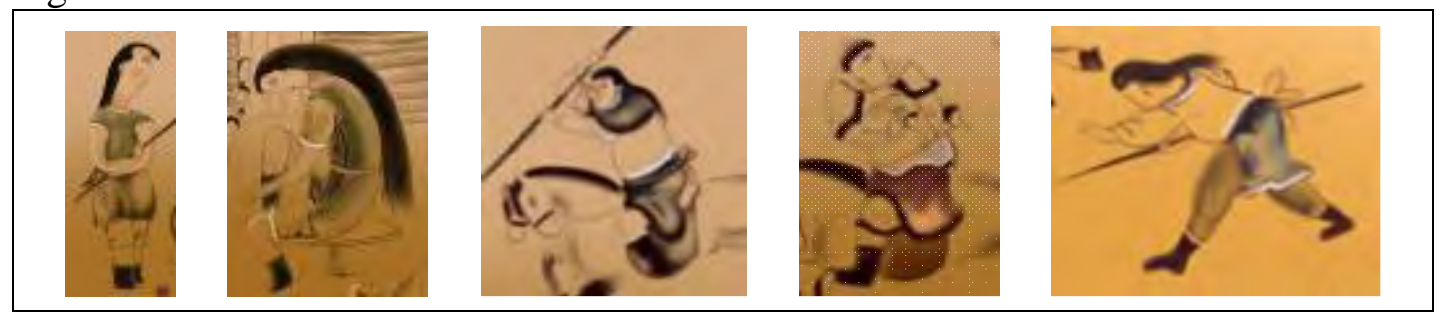

Fig. 8 The shape of a legendary figure with exaggerated proportions

\section{The Image Plot Design with the Symbolic Meaning Highlighted}

The author has paid great attention to the arrangement of time and space, which was to enrich the level of pictures. Many features of the Xibe feature extend the imagination space to increase the fluidity of the picture. ${ }^{\text {(Fig. 9) }}$ 

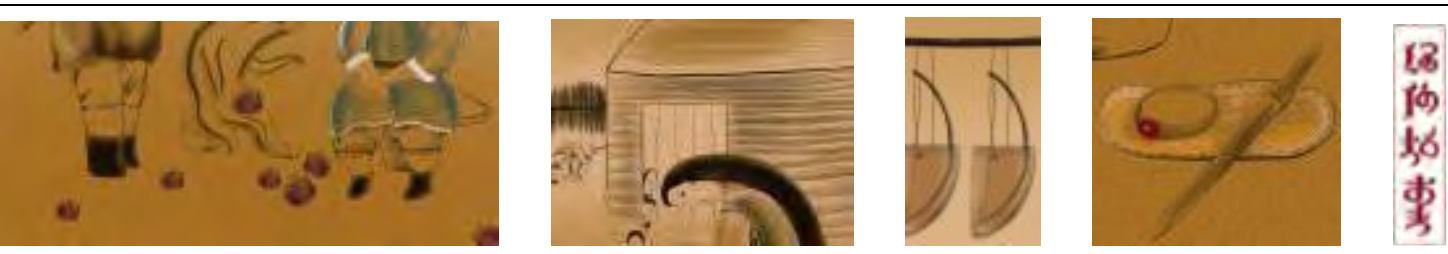

Fig. 9 The Xibe nationality's clothing, tent, reward and Xibe character's deformation Image Scene Combination of the Whole System

By arranging the scene elements, plot and scene, and various elements in the picture, it has beauty of order indeed. It is not arranged blindly with some certain order, but from an aesthetic point of view. The characters, plots and scenes are considered comprehensively to achieve the effect of unity and harmony. (Fig. 10)

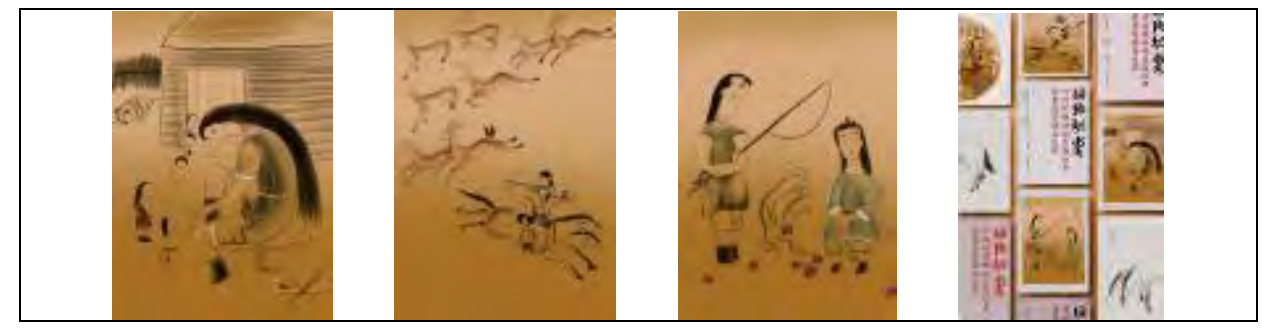

Fig. 10 Systematic overall composition

In the same structural reorganization, the Xibe people were declined to chose a variety of colors such as brown, blue, gray and so on, which was caused by their nomadic fishing and hunting environment. On the one hand, different kinds of colors were used according to the categories of objects and the status of characters. On the other hand, different colors have been chosen to convey their charm images better. Through concise colors to outline their costumes and utensils, the images of the characters are more vivid and full of charm.

\section{Conclusion}

By transforming and refining the modeling elements of heroic characters, story plots and characteristic scenes respectively in the legendary deeds of Xibe's novel form Junyou He, the symbiotic image character modeling, the spatio-temporal composite image plot combination and the whole image scene in the system are systematically discussed Under the idea of image modeling for the design conception of illustration creation. Finally, relying on the five creative methods of "image modeling", that is Multifaceted modeling of common elements, Multidimensional body modeling, A highly exaggerated body shape, Plot design with symbolic meaning and Scene combination of the system as a whole, the illustrations were created to help the sustainable development of Xibe's regional cultural symbols.

\section{References}

[1] Fan Jiang. The Epic of the Xibe People__"Legendary Deeds of Xibe's Novel form Junyou He". Northwest National Research.(2010)

[2] Sheng Shen.Visual Language Research on Animation Role Design. Publishing House of Jiangnan University. (2006)

[3] Visual China. Interpretation of Illustration Design. Beijing: Publishing House of electronics Industry.(2007)

[4] Stenven R.Gilmore Switzerland.photo Graphics.(2007) 
[5] VICTIOMDESIGN WORKSHOP.Victionary.one:flavor.I.(2002 )

[6] Zhibiao Zhang . Image Modeling and Color Analysis of Traditional Meticulous Figure Painting.(2015)

[7] Chengchen Li . The Discussion on the Stylization of Female Styling in Traditional Painting. Nanjing: Nanjing Arts Institute.(2016) 